\title{
A Mini-Review on Commonly used Biochemical Tests for Identification of Bacteria
}

\author{
Muhammad Shoaib $^{1 *}$, Iqra Muzammil², Muhammad Hammad ${ }^{1}$, Zeeshan Ahmad \\ Bhutta $^{3}$, Ishrat Yaseen ${ }^{4}$ \\ ${ }^{1}$ Institute of Microbiology; Faculty of Veterinary Science, University of Agriculture, Faisalabad-38000, Pakistan \\ ${ }^{2}$ Department of Clinical Medicine \& Surgery; Faculty of Veterinary Science, University of \\ Agriculture, Faisalabad-38000, Pakistan \\ ${ }^{3}$ Royal (Dick) School of Veterinary Studies, The University of Edinburgh, UK \\ ${ }^{4}$ School of Medical Sciences, Johar Institute of Professional Studies, Lahore, Pakistan \\ *Corresponding author: shoaibsinko8@gmail.com
}

\begin{abstract}
Bacteria are pathogenic microorganisms causing a number of diseases in humans from light to life threatening conditions. For proper treatment of patients infected with these diseases require proper diagnosis of diseases causing bacterial agent. As the bacteria are divided into two main as Gram Positive and Gram Negative Bacteria. Both type of bacteria exhibit a number of inherited biochemical properties by which we can differentiate, can check there presence and absence, can check their gram negative and gram positive nature. Therefore, the present review is focused to describe different biochemical tests in one article.

Published by IJRP.ORG. Selection and/or peer-review under responsibility of International Journal of Research Publications (IJRP.
\end{abstract}

Keywords: Microorganism, Bacteria, Biochemical Tests

\section{Introduction}

Biochemical tests are used for microbial identification based on difference lye in their biochemical activities exhibited by different types of bacteria. Different biochemical tests are listed below that are used for identification of gram positive and negative bacteria.
i. Catalase Test
ii. Coagulase Test
iii. Oxidase Test
iv. Indole Test
v. Sulfur Test
vi. Urease Test 
vii. Triple sugar iron test

viii. Nitrate Test

ix. Starch Hydrolysis Test

x. Carbohydrate Fermentation Test

xi. Methyl Red Test

xii. Voges-Proskaur Test

xiii. Citric Acid Utilization Test

xiv. Bile Esculin Agar Test

xv. Analytical Profile Index Test

\subsection{Catalase Test}

Test is used to check microorganisms that produces the catalase enzyme. Catalase enzyme produced by these bacteria will neutralize the hydrogen peroxide and bubbles will be produced that are indicative of positive test. Mostly, catalase enzyme is produced by obligate aerobes and facultative anaerobic bacteria. The test is performed by tube or slide method by mixing the colony of bacteria with few drops of $3 \% \mathrm{H}_{2} \mathrm{O}_{2}$ on slide or to the test tube and looking for bubble formation within 10 seconds (Facklam and Elliott, 1995).

\subsection{Coagulase Test}

Following test is used to recognize the bacteria having the ability to produce the coagulase enzyme. Mostly, help to identify the Staphylococcus aureus which is positive bacteria for coagulase test and catalase test. Among the virulence of factors of $S$. aureus, coagulase is one of them. Coagulase enzyme will coagulate the blood plasma during reaction process. This test is performed by mixing the blood plasma with colony of bacteria. Bacteria will produce the coagulase enzyme that will coagulate the blood plasma indicative of positive reaction (Holt et al. 1994).

\subsection{Oxidase Test}

Oxidase test is helpful in the identification of microorganisms having ability to produce cytochrome oxidase enzyme. The test helps to differentiate oxidase positive Pseudomonacea and negative Enterobacteriacea families. Cytochrome oxidase based on the principle of transfer of electrons from donor (Electron transport chain) to final acceptor (oxygen) and reduction will takes place in the form of water. Cytochrome oxidase will oxidize the electron donor and the color will change to dark purple. This test is performed by impregnation of 1 percent tetra-methyl-p-phenylenediamine dihydrochloride acting as artificial electron donor into a filter paper and dried. The bacterial colonies are smeared on paper strip and check for color change within $10 \mathrm{sec}$ (Win et al. 2006). 


\subsection{Indole Test}

Following test is helpful in the identification of to bacteria having the ability to produce tryptophanase enzyme. This enzyme will convert tryptophane amino acid into indole gas. Thus gas can be checked by adding different reagents such as Ehrlich's reagent or Kovac's reagent. Kovac's indicators contain paradimethyl amino benzaldehyde in isoamyl alcohol and conc $\mathrm{HCl}$ while Ehrlich's contain ethanol instead of isoamyl alcohol. Indole gas reacts with the reagent and the red color rosindole dye will form which indicates positive test (MacFaddin, 2000).

\subsection{Sulfur Test}

Sulfur test is helpful in the identification of microorganisms having the ability to produce cysteine desulfurase enzyme. This enzyme catabolize the cysteine (amino acid) or reduce it to thiosulphate that will reduce the sulfur into hydrogen peroxide. Due to the production of hydrogen sulfide the color of medium changes to black color. Proteus mirabilis is a sulfur positive organism (Barton et al. 2009).

\subsection{Urease Test}

Urease test helps in the identification of microorganisms having ability to produce urease enzyme. This enzyme belong to the amidohydrolases and phosphodoesterases superfamilies. Urease causes the hydrolysis of urea into $\mathrm{NH}_{3}$ and carbon dioxide. The ammonia formation will change the $\mathrm{pH}$ of the medium to alkaline and color will also change to pink at $\mathrm{pH} 8.1$ indicating positive results. This test is used to identify the Helicobacter pylori that is urease positive. The test is performed by placing mucosa of infected stomach or colonies of bacteria in urea broth. A change in color within 30 minute indicate positive test (Bailey and Scott, 1974).

\subsection{Triple Sugar Iron Test}

This test is helpful in the identification of microorganisms belong to Enterbacteriacea members. The test medium is consist of 3 sugars, Glucose 0.1percent, lactose and sucrose 1 percent each. Phenol red and ferrous sulphate are used as an indicator. The medium is prepared as butt and slant. The inoculated bacteria utilizes the glucose and glucose con is kept low as compared to other sugars. If the bacteria is able to utilize glucose in both aerobic and anaerobic conditions, both slant and butt color will change to yellow due to acid production within 6-8 hours of inoculation. If the bacteria have the ability to utilize the sucrose and lactose the acid production will remain continue and color of media will remain yellow. If it cannot utilize sucrose or lactose the bacteria starts utilizing the amino acids and makes the media alkaline that will change the color of medium into red due to phenol red. If the bacteria is strict aerobe then the color of butt will not change and reaction only will occur in slant. If the bacteria is facultative anaerobe, reaction will occur in both. Production of hydrogen peroxide gas by reduction of thiosulfate by many species of bacteria is evidenced by rising or 
breaks of agar medium (Harley, 2005).

\subsection{Nitrate Test}

Nitrate test is helpful to identify the microorganisms having the ability of reducing the nitrate into nitrite by the release of nitratase enzyme. This test is helpful for the identification of Gram +ve and Gram -ve bacterial species. The test tubes containing the nitrate broth were incubated after addition of bacterial colonies that we want to test. The tubes are incubated and first checked for presence of gas in Durham tubes. Non fermenter bacteria will not ferment the nitrate and nitrate will reduced to nitrogen gas. Sometime, gas can also be produced due to fermentation process will require further testing, that will be done to check nitrate reduction. For this process, add sulfanilic acid (also represented as nitrate I) and dimethyl-alpha-napthalamine (also represented as nitrate II). The presence of nitrite in the media If the nitrite will present in the medium it will react with both reagents I and II. Due to this reaction red color will form indicating positive result while no red color formation indicate either nitrate has not changed to nitrite or converted to nitrite that instantly converted to other non-detectable shape of nitrogen. For further checking zinc is added to the broth that will change any remaining nitrate into nitrite and formation of red color indicate confirm negative outcomes and if no color development even after addition of zinc indicate nitrate has been changed to nitrite and then changed to other forms indicate positive result (MacFaddin, 2000).

\subsection{Starch Hydrolysis Test}

This test is helpful in the identification of microorganisms that can produce the alpha amylase and oligo-1, 6glucosidase that causes the hydrolysis of starch. Often used to differentiate Clostridium and Bacillus. Starch is

a large molecule and cannot cross the bacterial cell wall to be used as carbon source. To convert starch into small molecules release enzymes that hydrolyze the starch into glucose that can enter into metabolic pathways and used as energy source. To check this iodine is added to the agar medium that will turn to dark brown color due to hydrolysis of starch indicating positive results (Hemraj et al. 2013).

\subsection{Carbohydrate Fermentation Test}

This test is helpful in the identification of bacteria that can ferment carbohydrate or those cannot ferment the carbohydrate. This test is based on the principle of acid or gas production. The type of media used for this test may be only glucose, sucrose or lactose (Hemraj et al. 2013).

\subsection{Methyl Red Test}

Some bacteria uses glucose and covert into other types of acids such as lactic acid (LA), acetic acid (AA) and formic acid (FA) as last products. First of all they covert glucose to pyruvic acid and then to different type of acids depends on the species of bacteria for which type of acid will be produced. Acid production decreases the medium $\mathrm{pH}$ that changes the color of the methyl red from yellow to red indicate the potential of bacteria to 
use glucose present in the culture medium (Crown and Gen, 1998)

\subsection{Voges-Proskaur Test}

This is the extension of Methyl red test and identify the organism having the potential to produce butylene as product. Acetoin is the in-between product of this reaction that is identified by using alpha-naphthol and 40 percent $\mathrm{KOH}$. Acetoin will be oxidized to diacetyl in the existence of $\mathrm{KOH}$. In the presence of alphanaphthol, Diacetyl will react with gunidine component of peptone and production of red color indicate positive test. This is done with the MR test (Bachoon et al. 2008).

\subsection{Citric Acid Utilization Test}

This test is helpful in the identification of microorganisms having the ability to use the citrate for the energy source. Citrate agar is used for this test containing citrate and inorganic ammonium for source of carbon and nitrogen respectively. CAU test is helpful in the identification of microorganisms that produce the enzyme citrate permease, that convert citrate into pyruvate and which then enters to metabolic cycle of organisms and produces energy and growth will appear on culture media. When microorganism utilize citrate, the $\mathrm{NH}_{3}$ will form due to conversion of the ammonium salts and the $\mathrm{pH}$ of medium will increase. The change in $\mathrm{pH}$ will change the color of bromothymol blue from green to blue when the $\mathrm{pH}$ rise above 7.6. Bromothymol blue is used as indicator in CAU test (Jawetz et al. 1989).

\subsection{Bile Esculin Agar Test}

This test is used to identify the microorganisms to hydrolyze the esculin in the existence of bile. This test is selective as well as differential medium for the identification of enterococcus. The selective medium are bile and sodium azide while differential medium is esculin. Bile will inhibit the growth of Gram positive bacteria except enterococci and few species of streptococci while sodium azide will stop the growth of Gram -ve bacteria. Bacteria having the capability to hydrolyze the esculin in the existence of bile will form esculetin that will react with ferric citrate present in the medium to form phenolic iron complex which will change the color of agar from dark brown to black indicate positive test e.g. E. faecalis. Color will be unchanged in case negative test (MacFaddin, 2000).

\subsection{Analytical Profile Index Test}

API is a type of classification of bacteria through tests for rapid identification of bacteria. By this, only known microorganisms can be identified. The AP20E/NE is the rapid identification system for limited number of Gram negative Enterbacteriacea family and non Enterbactriacea. The other API system is for Gram positive microorganisms such as Staphyloccoccus species, Micrococcus species and other related organisms. The AP 20E/NE system comprise of 20 small reaction mixture wells having dehydrated substrates to determine the enzymatic activity performed by bacteria. The activities are related with fermentation of carbohydrates, 
proteins and catalysis of amino acids by inoculated bacteria. First of all known bacteria colonies are mixed with sterile distilled water and then added to all wells to rehydrate the wells and then strip is incubated for specified time at specific temperature. After incubation the change in the color of all wells in noted. All the results are composed and a profile number is obtained which is then compared with profile numbers available online or in a commercial codebook for identification of bacterial species (Sugiartha et al. 2018).

\section{Conclusion}

Among the biochemical tests such as catalase test, coagulase test, starch hydrolysis test, and nitrate test are used to identify the Gram positive bacteria while oxidase test, urease test, indole test, sulfur test, methyl red / voges-proskauer test are used for the identification of Gram negative bacteria. Analytical profile index test $20 \mathrm{E}$ is developed to identify the members of Gram negative Enterbacteriacea family and non Enterbactriacea. API system is also developed for Gram positive microorganisms such as Staphyloccoccus species, Micrococcus species and other related organisms.

\section{References}

Bachoon., Dave, S, Wendy, A, Dustman., 2008. Microbiology Laboratory Manual. Ed. Michael Stranz. Mason, OH: Cengage Learning. Exercise 15, "Normal Flora of the Intestinal Tract" Print.

Bailey, W. R., Scott, E, G., 1974. Diagnostic microbiology, 4th ed. Mosby, St. Louis, MO.

Barton, Larry, L., Fauque, Guy, D., 2009. "Biochemistry, Physiology and Biotechnology of Sulfate Reducing Bacteria", Advances in Applied Microbiology 68, p. 41-98.

Holt, J, G., Krieg N, R., Sneath, P, H, A., 1994. Bergey's manual of determinative bacteriology. 9th. Balt William Wilkins.

Crown, ST.,Gen, J., 1998. Micromethod for the methyl red test Microbiol. 9 p. 101-109.

Harley, J, P., 2005. Laboratory exercises in microbiology, 6th ed. McGraw Hill, New York, NY.

Hemraj, V., Diksha, S, Avneet, G., 2013. A review on commonly used biochemical test for bacteria, Innovare Journal of Life Sciences, 1(1), p. 1-7.

Jawetz, E., et al., 1989. Medical Microbiology, Eighteenth Edition. (Appleton and Lange: San Mateo).

MacFaddin, J, F., 2000. Biochemical tests for identification of medical bacteria, 3rd ed. Lippincott Williams \& Wilkins, Philadelphia, PA.

Facklam, R., Elliott, J, A., 1995. Identification, classification, and clinical relevance of catalase-negative, gram-positive cocci, excluding the streptococci and enterococci. Clinical Microbiology, 8(4), p. 479.

Sugiartha, I, E., Semedi, B. P., Wardhani, P., Rejeki, I, P, S., 2018. Comparison results of analytical profile index and disc diffusion antimicrobial susceptibility test to Technical Dedicated Reasonable 300Bmethod, Indonesian Journal of Clinical Pathology and Medical Laboratory, 23(2), p. 131-137.

Winn, W., Allen, S., Janda, W., Koneman, E., Procop, G., Schreckenberger, P., Woods, G., 2006. Color atlas and textbook of diagnostic microbiology, 6th ed. Lippincott Williams \& Wilkins, Philadelphia, PA. 